Viso - Cadernos de estética aplicada Revista eletrônica de estética

ISSN 1981-4062

$N^{\circ} 4$, jan-jun/2008

http://www.revistaviso.com.br/

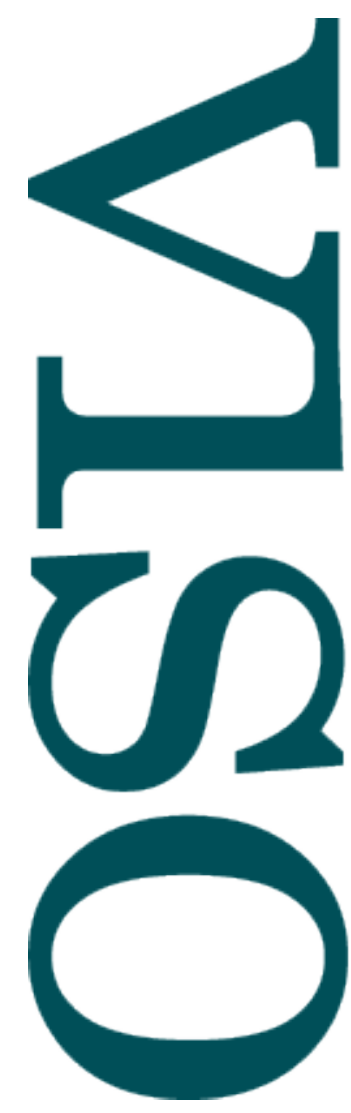

\title{
Greenberg, Danto e a crítica: problemas de um triângulo Guilherme Foscolo
}




\section{RESUMO}

Greenberg, Danto e a crítica: problemas de um triângulo

O que é a arte? Se elegemos critérios que nos permitem distinguir obras boas de obras ruins, até que ponto estes critérios são objetivos? Até que ponto é possivel, portanto, o exercício objetivo da crítica? O presente artigo pretende ser uma reflexão, mediante a fricção dos pensamentos de Clement Greenberg e Arthur Danto, acerca de dois problemas fundamentais para a filosofia da arte: o problema da definição (o que é arte?) e o problema do julgamento (ou da crítica).

Palavras-chave: arte contemporânea - Danto - Greenberg - crítica

\section{ABSTRACT}

Greenberg, Danto and criticism: problems of a triangle

What is art? If we adopt criteria to discern between "good" and "bad" works of art, to what extent can they be called objective? To what extent is it then possible to do any objective criticism? Based on a tension between the thoughts of Clement Greenberg and Arthur Danto, this paper intends to be a reflection on two of the most fundamental problems (and also on developments of these problems) concerning aesthetic philosophy: the problem of definition (what is art?) and the problem of judgment (or criticism).

Keywords: contemporary art - Danto - Greenberg - art criticism 
FOSCOLO, G. "Greenberg, Danto e a crítica: problemas de um triângulo". In: Viso: Cadernos de estética aplicada, v. II, n. 4 (jan-jun/2008), pp. 84-94.

DOI: $10.22409 / 1981-4062 / v 4 i / 59$

Aprovado: 01.06.2008. Publicado: 30.06.2008.

(C) 2008 Guilherme Foscolo. Esse documento é distribuído nos termos da licença Creative Commons Atribuição-NãoComercial 4.0 Internacional (CC-BY-NC), que permite, exceto para fins comerciais, copiar e redistribuir o material em qualquer formato ou meio, bem como remixá-lo, transformá-lo ou criar a partir dele, desde que seja dado o devido crédito e indicada a licença sob a qual ele foi originalmente publicado.

Licença: http://creativecommons.org/licenses/by-nc/4.0/deed.pt_BR

Accepted: 01.06.2008. Publicado: 30.06.2008.

(C) 2008 Guilherme Foscolo. This document is distributed under the terms of a Creative Commons Attribution-NonCommercial 4.0 International license (CC-BY-NC) which allows, except for commercial purposes, to copy and redistribute the material in any medium or format and to remix, transform, and build upon the material, provided the original work is properly cited and states its license.

License: http://creativecommons.org/licenses/by-nc/4.0/ 
Há alguns anos atrás, ouvi uma história impressionante acerca de uma exposição que ocorria no MASP. Durante o evento, uma certa área do museu havia sido isolada para reforma - os materiais e ferramentas foram mantidos ali, separados do público por uma fita amarela. Quando passavam pela reforma muitas pessoas não percebiam que aquilo se tratava, de fato, de uma mera reforma: alguns chegavam a parar e "apreciar" a disposição dos instrumentos espalhados, do montante de areia, da fita amarela.

O caso do MASP (meu correspondente particular daquilo que a caixa Brillo foi para Danto) pode até parecer piada - mas já não é novidade que, desde os primeiros ready made de Duchamp, praticamente desapareceu o limite que separa aquilo que é arte daquilo que não é. A coisa se tornou tão sintomática que, décadas depois, Arthur Danto iria reconhecê-la como o Problema (com P capital) da filosofia da arte - se qualquer objeto, ou melhor, se qualquer coisa pode ser elevada à categoria de arte, torna-se uma missão impossível para o espectador diferenciar uma intervenção não artística (a reforma do MASP) de uma intervenção artística (pelo menos não sem a ajuda de signos complementares, tais como placas de identificação). O "será arte tudo o que eu disser que é arte" de Duchamp serve de prenúncio a uma era em que tudo é possível para a arte - ou, nas palavras de Danto, em que tudo pode ser arte.

Danto só pode chegar a esta conclusão ao identificar um momento de ruptura, de descontinuidade com a maneira como se vinha fazendo e avaliando objetos de arte desde o início da chamada "Era da Arte", ou seja, do Renascimento para frente. Como não existe mais uma forma específica que determine como as obras de arte devem ou não ser produzidas, a história das narrativas alcança enfim um final: e é este final, como veremos mais adiante, que Danto identifica com o fim da história da arte. Clement Greenberg não pôde enxergar a ruptura nestes termos, mas chegou bem próximo de fazê-lo. Greenberg redefine a história da arte a partir do Modernismo como história da pureza, isto é, se há uma continuidade com o modelo vasariano de evolução artística, esta evolução não está na mímese - e sim na aquisição de "graus" de pureza cada vez mais elevados.

Seja como for, tanto Danto quanto Greenberg foram partícipes diretos da história da arte no século XX; penso que friccionar o pensamento de ambos pode ser um bom ponto de partida para discutir a pertinência ou não de pelo menos duas grandes questões da filosofia da arte em nosso tempo: a primeira, relativa à definição; a segunda, relativa ao julgamento. A primeira pergunta: o que é arte? E a segunda: como é possível definir se determinada obra é melhor ou pior que outra? Com sorte, talvez seja possível trazer à tona alguns problemas relativos a qualquer tentativa de se chegar a uma conclusão bem delimitada das questões acima propostas.

Antes de mais nada, creio ser importante apontar o que diferencia o movimento histórico que marca a arte no início do século XX dos movimentos históricos anteriores - isto é, o que faz do Modernismo um capítulo especial na história da arte. Partindo de um ponto comum, Greenberg e Danto concordam que o Modernismo inaugura uma nova era para 
as artes pictóricas: a arte moderna coloca em primeiro plano as características nãomiméticas da pintura. Isto só é possível porque o Modernismo opera um movimento bem próximo daquele operado por Kant em sua Crítica da Razão Pura: da mesma forma que a Razão vira-se para si mesma a fim de investigar sua própria natureza, a arte vira-se para si mesma e acaba também - para parafrasear Danto - tornando-se seu próprio assunto. A diferença está na direção tomada por cada um a partir daí: de um lado, Greenberg e o "purismo"; de outro, Danto e o "pluralismo". Para Greenberg, o "virar-se para si mesma" levaria necessariamente cada arte a identificar aquilo de único na natureza de seus meios. Cada arte deveria se aferrar àquilo de específico de seus próprios meios materiais e se livrar dos efeitos tomado dos meios de quaisquer outras artes - "assim, cada arte se tornaria 'pura', e nessa 'pureza' iria encontrar a garantia de seus padrões de qualidade, bem como de sua independência”. ${ }^{1}$ A mímese deveria ser abandonada, portanto, como meio de dissimulação tomado da escultura, cedendo lugar às características próprias da pintura: a planaridade, a própria tela, as tintas, etc. Daí a grande aposta de Greenberg na pintura abstrata, e particularmente por algum tempo no expressionismo abstrato norte-americano. A arte abstrata representaria o ponto culminante de uma narrativa histórica inexorável ${ }^{2}$ :

\begin{abstract}
$\mathrm{Na}$ verdade, boa parte dos artistas - senão a maioria - que deu contribuições importantes para o desenvolvimento da pintura moderna chegou a ela com o desejo de explorar a ruptura com o realismo inativo em busca de uma expressividade mais forte, mas a lógica do desenvolvimento foi tão inexorável que, no final das contas, sua obra não passou de um degrau a mais rumo à arte abstrata, e a uma maior esterilização dos fatores expressivos. Foi assim com Van Gogh, Picasso ou Klee. Todos os caminhos levaram ao mesmo lugar. ${ }^{3}$
\end{abstract}

Se, para Greenberg, a modernidade marca o início de um processo de limpeza de campo nas artes, Danto vê o mesmo fenômeno engendrar o início de uma crise: a era dos "ismos" desemboca exatamente no oposto do purismo que marca seu começo - o último "ismo" corresponde a um "pluralismo" em que tudo é permitido. Danto pensa a história da pintura como história das narrativas, dividindo-a assim em dois principais episódios de natureza progressiva: o "episódio Vasari" e o "episódio Greenberg". O episódio Vasari (século XIV ao XIX) caracteriza-se pela prevalência da narrativa mimética, enunciada, é claro, por Giorgio Vasari - ou seja, a arte deveria se pautar por uma progressiva conquista das aparências. $\mathrm{O}$ advento da fotografia e, mais tarde, do cinema, colocou um fim à era vasariana. Com o fim da era vasariana, a pintura realiza um movimento introspectivo e, perguntando-se acerca da própria função, abre as portas para um novo modelo narrativo: entra em cena a busca pela identidade. A narrativa greenbergiana caracteriza-se assim pela busca do ideal de "pureza" - cada arte progressivamente deveria se entricheirar naquilo que possui de mais próprio em seu meio material. O fim do episódio Greenberg coincide com o surgimento da arte pop 
(meados da década de 60): a arte pop anuncia o fim da arte, "quando a arte reconheceu que não havia uma aparência especial que devesse ser assumida como própria da obra de arte" ${ }^{4} \mathrm{~A}$ arte produzida após a pop destaca-se da arte produzida no Modernismo na medida em que se livrou das estruturas narrativas: tornou-se, neste sentido, arte póshistórica - arte contemporânea.

Procurarei demonstrar agora como a concepção de progressividade na história da arte assumida por Greenberg acaba por determinar o que a arte deve ser, o que não faz a concepção filosófica sugerida por Danto. Partirei, como já fiz ao tratar do Modernismo, de mais um ponto aparentemente comum: se a interpretação de ambos os autores acerca do Modernismo coincide em apenas um ponto preciso, as divergências daí resultantes não impedem que ambos defendam uma concepção imutável acerca do que é arte. No caso de Greenberg, esta concepção assume a forma de uma imutabilidade conduzida pelo gosto; no caso de Danto, de uma espécie de essencialismo filosófico. De tudo o que li não encontrei em Greenberg melhor resposta para a pergunta "o que é arte?" do que a exposta em seu texto "O juízo e o objeto estético". Greenberg abre sua exposição da seguinte forma:

Afirmei anteriormente que não era possivel estabelecer nenhuma diferença entre o estético e o artístico; que toda experiência estética deveria ser considerada arte. Mas fui obrigado a levar em conta a diferença entre a experiência estética em seu estado mais bruto e abrangente - que denominei "arte crua" - e o gênero de experiência estética comumente reconhecido como arte - que denominei de arte "formalizada" ou "formal".

Se toda experiência estética deve ser considerada arte, isto quer dizer que nós humanos produzimos arte desde quando produzimos experiências estéticas - até onde sei, desde que nos entendemos por seres humanos. Qualquer situação pode ser vivida esteticamente, desde que a experiência recue sobre si mesma, possibilitando assim uma participação passiva na própria experiência vivida. Ou seja: "a experiência estética é a experiência da experiência". ${ }^{6}$ Arte formalizada é o que acontece com a experiência estética quando se deseja torná-la comunicável, pública. A comunicação da experiência estética exige que a mesma seja submetida a determinadas convenções - tais convenções (ou formas) demarcam o campo da arte formalizada. A progressividade histórica faz com que só seja possível à arte formal - se pretende ser arte de qualidade (ver nota 1) - aderir às convenções elegidas por seu próprio tempo. Não há nada na natureza de qualquer arte que a leve a ser necessariamente desta ou daquela maneira "o imperativo", como diz Greenberg, "vem da história". ${ }^{7} \mathrm{Em}$ última instância, as convenções estabelecidas historicamente submetem-se ao "gosto" de cada época; o que equivale a dizer que a arte é sempre a mesma, e sua formalização é determinada historicamente pelo gosto.

Em Danto, a resposta é relativamente mais simples: se após o "fim da arte" tudo pode ser uma obra de arte, a pergunta "o que é arte?" deixa de fazer sentido. Uma definição filosófica da arte não poderia excluir nada, uma vez que a arte está a partir de então liberada da história (isto é, das definições históricas que tinham por função delimitar 
aquilo que ela deveria ser). Uma definição filosófica da arte que seja abrangente o bastante para captar todas as suas manifestações deve ser, portanto, essencialista e extra-temporal. Ela deve assumir que as definições acerca da natureza da arte anteriores ao fim da arte não passaram de mascaramentos. Se o fim da história da arte anuncia a validade artística de praticamente qualquer coisa, ele também torna imperativa uma definição filosófica trans-histórica da arte: todos os momentos históricos anteriores devem ser tomados em sua totalidade, uma vez que a "essência" da arte só se revela por meio da história. "A verdadeira descoberta filosófica", diz Danto, "penso ser, na verdade, que não existe uma arte mais verdadeira do que outra, bem como não há uma única forma que a arte necessariamente deva assumir: toda arte é igual e indiferentemente arte". ${ }^{8}$ Concluindo: se para além do essencialismo filosófico (ou da imutabilidade greenbergiana) aquilo que caracteriza a arte está também atrelado a um momento específico na história, em Greenberg esta história conduz inexoravelmente ao purismo (ela limita); para Danto, a narrativa histórica do purismo leva a arte a um esgotamento interno do qual ela só pode se libertar tornando-se pós-histórica, ou seja, abrindo as portas para todas as possibilidades. Passemos enfim à segunda pergunta: é possível distinguir a arte boa da ruim?

Quero retomar a discussão acerca da experiência estética em Greenberg. Havíamos dito que, para Greenberg, "a experiência estética é a experiência da experiência". Não se pode jamais recuar, entretanto, da experiência estética propriamente dita: e isto porque os juízos estéticos são inseparáveis de seus objetos ou circunstâncias específicas. A experiência estética deve sempre ser uma experiência direta do sujeito, o que equivale a dizer que ela é intransferível. Com isso, Greenberg quer dizer que fazer arte e apreciar arte pertencem, em último grau, à mesma ordem da experiência. Isto se dá porque a experiência estética não está dissociada do juízo de gosto, e a intuição estética por parte de quem faz a obra coincide com seu próprio juízo de gosto. O produtor (considerando a arte formal) faz julgamentos assim como o apreciador o faz. Deste modo, o artista toma decisões estéticas que pode experimentar, assim como o apreciador, em sua própria obra.

A simetria entre o artista e o observador se dá, para Greenberg, no momento em que o objeto de arte pronto é exibido para o apreciador: este "recebe o resultado do gosto aplicado", o artista recebe "o resultado da aplicação do seu próprio gosto". 9 distanciamento estético é o que estabelece a simetria, bastando que a intuição estética decida tudo sozinha. Seja como for, a qualidade de qualquer obra estará diretamente associada à densidade das decisões-juízo efetuadas por seu criador. Isto funciona do seguinte modo: as convenções de determinada época direcionam o artista a formalizar sua experiência estética deste ou daquele modo - o meio material em que se dá a formalização oferece resistência ao artista, e ser bem sucedido na realização da obra significa encontrar soluções originais para a resistência oferecida. Lidar com aquilo que é próprio do meio material de cada arte é a maneira correta de lidar com o problema de frente - neste sentido, a perspectiva na pintura teria sido uma maneira de negar a 
planaridade da tela, escapar de um enfrentamento direto com o meio. Mas de que forma o crítico pode asseverar esta qualidade? De que forma qualquer um pode asseverá-la?

A única forma de se escapar de um subjetivismo "solipsista" no que concerne à qualidade é através da eleição de critérios objetivos e universais. Penso que uma das contribuições mais importantes de Greenberg está na reabilitação do gosto enquanto critério - não um gosto subjetivo, ao contrário, Greenberg aposta na objetividadedo gosto. Seu argumento é o seguinte: os juízos estéticos são involuntários - uma pessoa não pode se decidir a gostar de determinada coisa, ela simplesmente gosta ou não gosta. Os juízos estéticos também não permitem a aplicação consciente de regras, teorias, etc, e são inseparáveis da experiência imediata. A experiência é, parafraseando Greenberg, o único tribunal de apelação do juízo estético. Não obstante, é impossível provar um juízo estético. Mas ao mesmo tempo só se pode qualificar a arte mediante o juízo estético impulsionado pela experiência.

Vejamos como isso se opera: em seu texto "Queixas de um crítico de arte", Greenberg assume a tarefa de examinar o que pode ser dito acerca de uma obra de arte. Se é possível realizar a distinção, pelo menos para fins analíticos, entre forma e conteúdo, então ao crítico ficaria vedado emitir qualquer opinião acerca do conteúdo - e isto porque nunca se pode dizer nada de significativo sobre o conteúdo de uma obra ("E se eu preferir dizer que Kline é pessimista, e não otimista, quem pode me contestar?"). ${ }^{10}$ Tudo o que se diz sobre o conteúdo é incontestável e, como tal, inútil para a crítica. Mas se só é possível criticar a forma, e se o juízo de gosto se dá de imediato - sem a intervenção de razões ou teorias - como é possível criticar a forma, que por excelência só pode ser criticada mediante a intervenção de razões ou teorias? A resposta de Greenberg:

Esses princípios qualitativos ou normas [padrões, critérios, regras, preceitos] sem dúvida estão presentes em operações subliminares; do contrário, os juízos estéticos seriam puramente subjetivos, e a prova de que não o são é o fato de que os veredictos daqueles que mais se preocupam com a arte e mais lhe dedicam atenção acabam por convergir ao longo do tempo, formando um consenso. ${ }^{11}$

Tais princípios qualitativos, no entanto, não podem ser postos em palavras. Sua existência só pode ser provada por seus efeitos - isto é, a existência de um certo consenso atingido por aqueles mais preocupados com a arte através do tempo. Em última instância, só a história poderá confirmar qualquer juízo acerca da qualidade de uma obra - trocando em miúdos, só a história poderá definir se o julgamento de um crítico acerca de determinada obra procede ou não procede. Em suma: para Greenberg a qualidade existe e é possível avaliá-la através do gosto praticado.

Danto participa, até certo ponto, da mesma opinião de Greenberg. Penso que a diferença crucial está na seguinte pergunta: como pode o olhar do crítico diferenciar aquilo que é arte daquilo que não é? Em Greenberg, como vimos, a crítica revela sua insuficiência em lidar com o pluralismo inaugurado pela arte pop ao considerar um caminho específico que as artes devam seguir - o purismo (que se identifica, no caso da pintura, com a 
pintura abstrata). A arte pop representaria, assim, apenas mais uma maneira de contornar a resistência oferecida pelo meio num momento histórico marcado pelo entrincheiramento das artes naquilo que elas têm de único - no caso da pintura, a planaridade. A pluralidade significa para Greenberg retrocesso histórico: em última análise, significa não apresentar soluções originais e produzir obras de qualidade inferior.

Em suma, a teoria crítica de Greenberg não daria conta desta nova realidade histórica ou melhor, pós-histórica - em que tudo é possível para a arte. Como vimos, no momento pós-histórico "toda arte é igual e indiferentemente arte" - igual e indiferentemente arte implica dizer que o conceito de qualidade tornou-se algo obsoleto. Quando digo obsoleto, quero dizer no seguinte sentido: já não cabe mais ao crítico definir se uma arte é mais verdadeira que outra, qual o caminho para se produzir arte de qualidade, ou melhor, para qual direção aponta o único caminho possível. Ora, se a qualidade neste sentido tornase obsoleta, o que resta para o crítico? A resposta de Danto, é claro, não poderia ser mais hegeliana: traduzir em palavras a adequação da forma ao conteúdo. ${ }^{12}$ Resta ao crítico traduzir em palavras a qualidade ainda possível. Talvez isso fique mais claro na passagem seguinte:

Concordo com Greenberg no seguinte ponto: existe um critério de qualidade para trabalhos como as pinturas pelos números de Warhol e para a caixa tagarela de Robert Morris, e, se nós exercitarmos a crítica de arte tendo em vista esses objetos, estaremos em uma possível melhor posição para apreciar o bom e o ruim nas obras modernas, como as pinturas de Mondrian e Pollock, bem como nas dos antigos mestres. Uma teoria geral da qualidade poderá então conter o esteticamente bom não como traço definidor, mas como caso especial. Pois espero ter demonstrado que o esteticamente bom não traria qualquer contribuição para a arte após o fim da arte..$^{13}$

Na minha opinião, é extremamente curioso o fato de Greenberg e Danto coincidirem num ponto tão controverso quanto $\mathrm{o}$ da possibilidade de crítica objetiva da arte: ambos concordam que deve haver critérios de qualidade (talvez por serem ambos críticos de arte?). Mas esses critérios nunca são colocados em palavras. A pergunta que me faço é a seguinte: por que devem existir critérios de qualidade?

Não me dou por convencido com a resposta de Greenberg: não acho que os efeitos sirvam para qualquer coisa que não seja especulação. Mesmo que assumíssemos a existência de "clássicos" (não consigo enxergar o consenso de que Greenberg tanto fala), o fenômeno poderia ser tão somente conseqüência da historicização do gosto de determinada época. Aquilo que elege o gosto de determinada época pode ser contingente: não há como afirmar condições únicas e universais de "bom gosto". Se devo concordar com Danto que a arte contemporânea assiste a um esgotamento das antigas categorias conceituais, não vejo como fazê-lo sem também estender o esgotamento para as antigas categorias de julgamento. Afinal, por que a crença em qualquer possibilidade de criticabilidade objetiva deve passar incólume? 
Neste sentido, talvez não tenhamos avançado mais do que os românticos de Jena: o conceito de não-criticabilidade do que é ruim assume que, se já é difícil definir o que é arte, definir se determinada obra é de boa ou má qualidade é tarefa impossível. Numa época em que tudo pode ser arte, acho que o critério da não-criticabilidade é quase autoimpositivo. Se o gosto é, na prática, a faculdade utilizada pelas pessoas na separação dos elementos estéticos que gostam dos que não gostam, por que não assumir simplesmente que todo gosto é, em última instância, subjetivo? O que há de tão temível na subjetividade do gosto? O que há de tão temível em constatar que não há absolutamente nada em Mozart que torne sua música intrinsecamente melhor, digamos, que o hard-rock de ACDC?

A falta de critérios objetivos não é necessariamente boa nem ruim. E nem tem que tornar obsoleta a função do crítico. Não vejo nenhum problema na constatação de que, se o gosto é subjetivo, a função do crítico resume-se a expor sua opinião pessoal - subjetiva - provinda da sua própria experiência ao manter contato com uma obra. Gostaria de encerrar reproduzindo o desfecho de um texto da crítica Rosalind Krauss sinceramente, a visão mais honesta que já encontrei acerca da função crítica. Nesta passagem, Krauss responde ao formalismo greenbergiano da seguinte forma:

Isso quer dizer também que insisto em considerar o "formalismo" como uma vulgaridade; que se comecei como crítica modernista e ainda sou uma crítica modernista, pertenço a uma sensibilidade modernista no sentido mais amplo, e não no sentido mais estrito do termo. Enfim, isso quer dizer que eu não tenho que dar conta de uma perspectiva universal, mas simplesmente de meu próprio ponto de vista; que importa quem damos a impressão de ser quando escrevemos sobre arte. Sua própria perspectiva, como sua própria idade, é a única orientação que uma pessoa jamais terá. $^{14}$

\footnotetext{
* Guilherme Foscolo é mestrando em filosofia pela UFMG.

${ }^{1}$ GREENBERG, C. Clement Greenberg e o bebate crítico. Org. Glória Ferreira e Cecília Cotrim de Melo. Tradução de Maria Luiza X. de A. Borges. Rio de Janeiro: Jorge Zahar, 2001, p. 102.

${ }^{2}$ Rosalind Krauss dá-nos um ótimo exemplo de como a opção pela crítica histórico-progressiva era manifesta na época do Modernismo. Em certa passagem de seu artigo "Uma visão do modernismo", ela nos relata algo como um depoimento: "A história que víamos, de Manet até os impressionistas e Cézanne, e depois até Picasso, era como uma série de salas en enfilade. Em cada uma dessas salas o artista explorava, até os limites de sua inteligência e de sua experiência formal, os constituintes específicos do seu meio. Seu ato pictórico tinha por efeito abrir a porta para o próximo espaço, fechando, simultaneamente, o acesso aos que o precedia. A forma e as dimensões do novo espaço eram descobertas pelo ato pictórico seguinte. Nessa situação instável, a única coisa acerca dessa posição instável prevista e claramente determinada era a via de acesso. Em 1965 era uma conclusão lógica que, para trabalhar no nível de Velásquez, Frank Stella tinha de pintar tiras". Cf. KRAUSS, R. "Uma visão do modernismo". In: GREENBERG, C. Op. cit., p. 167.
} 
${ }^{3}$ GREENBERG, C. Op. cit., p. 58.

${ }^{4}$ DANTO, A. Após o fim da arte: A arte contemporânea e os limites da história. Tradução de Saulo Krieger. São Paulo: Odysseus Editora, 2006, p. 139.

${ }^{5}$ GREENBERG, C. Estética doméstica - Observações sobre a arte e o gosto. Tradução de André Carone. São Paulo: Cosac \& Naif, 2002, p.87.

${ }^{6}$ Ibidem, p. 88.

7 "É suficiente dizer que não há nada na natureza da arte abstrata que a force a ser assim. O imperativo vem da história, da época em conjunção com um momento particular alcançado numa tradição particular da arte. Essa conjunção mantém o artista numa situação da qual, no presente momento, ele só pode escapar abrindo mão de sua ambição e retornando a um passado gasto". Cf. GREENBERG, C. Clement Greenberg e o debate crítico. Org. Glória Ferreira e Cecília Cotrim de Melo. Tradução de Maria Luiza X. de A. Borges. Rio de Janeiro: Jorge Zahar, 2001, p. 58.

${ }^{8}$ DANTO, A. Op. cit., p.38.

${ }^{9}$ GREENBERG, C. Estética doméstica - Observações sobre a arte e o gosto. Tradução de André Carone. São Paulo: Cosac \& Naif, 2002, pp. 90-91.

${ }^{10}$ GREENBERG, C. Clement Greenberg e o debate crítico. Org. Glória Ferreira e Cecília Cotrim de Melo. Tradução de Maria Luiza X. de A. Borges. Rio de Janeiro: Jorge Zahar, 2001, p. 121.

${ }^{11}$ Ibidem, p. $117 .$.

12 "Na famosa passagem já citada sobre o fim da arte, Hegel fala do juízo intelectual do '(i) conteúdo da arte, e do (ii) meio de apresentação da obra de arte'. A crítica não precisa ir mais longe do que isso. Não precisa identificar sentido e modo de representação, ou o que denomino 'corporificação' com base na tese de que as obras de arte são sentidos corporificados. O erro da crítica de arte kantiana esteve em segregar forma e conteúdo. A beleza é parte do conteúdo das obras que ela valoriza, e seu modo de apresentação nos pede uma resposta sobre o sentido da beleza. Tudo isso pode ser posto em palavras quando se faz uma crítica de arte. Traduzir em palavras é aquilo em que consiste a crítica". Cf. DANTO, A. Op. cit., p. 109.

${ }^{13}$ Ibidem, p. 106.

${ }^{14}$ KRAUSS, R. “Uma visão do modernismo”. In: GREENBERG, C. Op. cit., p. 173. 